\title{
Polímeros e a Indústria Automobilística
}

\author{
Carlos A. Hemais \\ IMA, UFRJ e COPPEAD, UFRJ
}

Resumo: Gradativamente, devido a razões econômicas e tecnológicas, nos últimos trinta anos, os plásticos passaram a ocupar um lugar de destaque como um dos materiais mais utilizados pela indústria automobilística. Este trabalho tem por objetivo identificar a intensidade do uso de polímeros pela indústria automobilística brasileira. Inicialmente é apresentada uma classificação dos polímeros, de acordo com suas características técnicas e econômicas. Em seguida, é feita uma breve explanação sobre a indústria de polímeros no Brasil, bem como sobre a indústria automobilística, com seu grande potencial de atrair inovações tecnológicas. São apresentados, também, os principais polímeros com aplicação no automóvel. Por último, é discutida a questão da inovação tecnológica na indústria brasileira de polímeros, tendo como fator catalisador a indústria automobilística.

Palavras-chave: Indústria automobilística, plásticos nos carros, classificação dos polímeros, commodity, quasi-commodity, polimeros de alto desempenho.

\section{Polymers and the Automobile Industry}

Abstract: Gradually, owing to economic and technological reasons, in the last thirty years, plastics have gained an increasing presence in automobiles. This paper examines the use of plastics in the Brazilian car industry. First, polymers are classified according to their technical and economic characteristics. The paper then reports briefly on the Brazilian polymer industry, as well as on the auto industry, focusing on its great potential for attracting technological innovations. The main applications for plastics in cars are also outlined. Finally, the paper discusses the question of technological innovation in the Brazilian polymer industry, with the auto industry as a catalyst.

Keywords: Auto industry, plastics in cars, classification of polymers, commodity, quasi-commodity, high-performance polymers.

\section{Introdução}

A substituição pela indústria automobilística de materiais tradicionais por plástico se deu de forma gradativa ao longo de vários anos, mas apenas nas duas últimas décadas é que o ritmo dessa substituição se acelerou. Razões diversas, tanto econômicas, quanto tecnológicas, influenciaram o andamento dessa mudança. As crises do petróleo de 1973 e de 1979 trouxeram a conscientização para o problema da escassez de combustível e para a vulnerabilidade do uso indiscriminado de recursos naturais de fontes não-renováveis. Essas crises podem ser consideradas como o momento decisivo da tomada de posição quanto à construção de carros mais eficientes, seguros, confortáveis e que consumissem menos combustível. Pode-se dizer, porém, que somente após a superação de limitações tecnológicas, com o desenvolvimento de polímeros de alto desempenho, é que os plásticos passaram a fazer parte essencial dos automóveis. Hoje, considerando-se o volume dos materiais, são usados mais plásticos do que aço na construção de um veículo, devido ao grande número de aplicações que os polímeros encontraram nesse produto.

A média de 30 quilos de polímeros empregada por veículo, na década de 70, passou a representar cerca de 180 quilos no final da década de 90 e estima-se que nos próximos cinco anos esse valor ultrapasse os 200 quilos ${ }^{[1]}$. A questão que ora se levanta, a partir do uso de plásticos na indústria automobilística, é sobre a disponibilidade de fornecimento de matériasprimas por parte da indústria de polímeros no Brasil.

Este trabalho apresenta inicialmente uma classificação dos polímeros, de acordo com suas características técnicas e econômicas. Em seguida, é feita uma breve explanação sobre a indústria de polímeros no Brasil e apresentado um comentário sobre a indústria automobilística com seu grande potencial de atrair inovações tecnológicas. São apresentados, também, os principais polímeros com aplicação no automóvel. Por último, é discutida a questão da inovação tecnológica na indústria brasileira de polímeros, tendo como fator catalisador a indústria automobilítica.

\section{Polímeros e seu valor agregado}

Os polímeros distinguem-se entre si pelo grau de diferenciação, escala de produção e nível de consumo e, conseqüentemente, valor agregado. Assim, de uma forma geral, os materiais poliméricos podem ser classificados em três grandes grupos: polímeros para usos gerais (commodities), polímeros para usos específicos (quasi-commodities) e polímeros de alto desempenho (especialidades). Polímeros tipo commodities são aqueles produzidos em grande

Autor para correspondência: Carlos A. Hemais, Grupo de Gestão Tecnológica, IMA, UFRJ, Caixa Postal 68525, CEP: 21945-970, Rio de Janeiro, R.J. E-mail:hemais@ima.ufrj.br 
escala, têm baixo valor agregado, não apresentam diferenciação, são utilizados para finalidades gerais e são consumidos em grandes quantidades. Os chamados polímeros quasi-commodities são, também, produzidos em grande escala, porém em nível mais baixo do que as commodities. Entretanto, quasi-commodities apresentam desempenhos diferenciados e propriedades que os fazem ser ideais para determinadas aplicações. Polímeros de especialidades são aqueles que apresentam alto desempenho, são produtos específicos, com propriedades bem definidas e incomuns, tem alto valor agregado e são produzidos em escalas de pequeno porte.

A Figura 1 é a representação gráfica desta classificação geral proposta. Verifica-se que quanto maior o volume de produção, maior é o consumo e menor é o grau de diferenciação, o preço e o conteúdo tecnológico. Por exemplo, os polímeros classificados no topo do triângulo (especialidades) são os que apresentam maior preço, diferenciação e conteúdo tecnológico, porém são produzidos e consumidos em menor escala e têm disponibilidade limitada a poucos produtores mundiais.

Como exemplos de commodities, citam-se os polietilenos, o polipropileno, o poli(cloreto de vinila) e o poliestireno. O típico polímero quasi-commodity é o PET, que tem características específicas de plásticos de engenharia e mercado bem direcionado, porém é produzido em grande escala. Poliamidas, ABS, SAN, poliuretanos e policarbonato também podem ser classificados nessa categoria. Entre os polímeros de alto desempenho, podem ser citados o poli(óxido de metileno) (POM), politetrafluoroetileno (PTFE), poli(tereftalato de butileno) (PBT), poli(sulfeto de fenileno) (PPS) e polímeros líquido-cristalinos.

Vale ressaltar que a classificação apresentada não é exaustiva, uma vez que polímeros tipo commodity, modificados ou em misturas com outros polímeros, podem ter propriedades que os possibilitem substituir polímeros de uso específico. Isto pode ser verificado nos diversos grades apresentados pelo polipropileno, por exemplo, que permitem o uso desse polímero em aplicações que exijam características especiais que, normalmente, não são encontradas em commodities. $\mathrm{O}$ mesmo pode ocorrer com quasi-commodities, como o PET

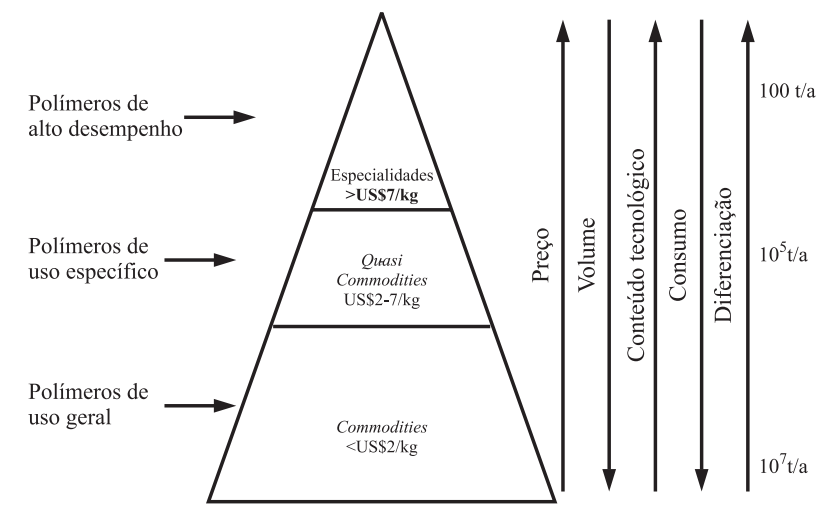

Figura 1. Classificação dos polímeros

Fonte: Baseado em Bomtempo ${ }^{[2]}$ grau-embalagem, que custa menos de $2 \mathrm{U} \$ \mathrm{~kg}$ e tem volume de produção equivalente a um polímero commodity.

De acordo com Bomtempo ${ }^{[2]}$, essa classificação representa uma visão centrada no produto, não incorporando a tendência de inovação dos polímeros existentes a partir das décadas de 80 . O polímero é visto mais como um conjunto de características de partida do que como uma busca de melhores respostas às limitações de preços e desempenho.

Apesar de suas limitações, a representação mostrada na Figura 1 serve bem para ilustrar a grande variedade de produtos existentes no mercado e as diferenças encontradas entre eles.

\section{Brasil e sua indústria de polímeros}

Pode-se dizer que a indústria de polímeros no Brasil passou a existir formalmente a partir da instalação, na década de 70 , de três polos petroquímicos. Anteriormente, existiam unidades isoladas produzindo um ou outro tipo de polímero, porém sem grande representatividade no PIB nacional.

Os polos foram instalados seguindo o modelo de substituição de importação, criando-se empresas tripartites, cuja composição acionária era composta de parte pertencente a Petroquisa, parte pertencente à empresa nacional de capital privado e parte a uma empresa estrangeira, geralmente detentora da tecnologia a ser utilizada. Assim, foram criadas empresas monoprodutoras, cuja principal atividade tecnológica estava ligada à adaptação de tecnologia licenciada por fornecedor estrangeiro ${ }^{[3]}$.

O processo de privatização das empresas ocorrido na década de 90, aliado à queda dramática nas alíquotas de importação de produtos poliméricos, mudou totalmente o perfil dessa indústria. Foram observadas fusões de empresas, desaparecimento de produtoras, saídas de sócios estrangeiros, bem como aquisições dos ativos existentes por parte de multinacionais estrangeiras de grande porte. Essas multinacionais, até então, tinham dificuldade de se estabelecer no país através de subsidiárias, independentes de controle governamental brasileiro, ou de ter acesso total e exclusivo às centrais de fornecimento de matérias primas.

O final da década de 90 apresenta uma nova configuração da indústria. A característica marcante de empresas monoprodutoras sem economia de escopo se modifica através do fortalecimento de grandes grupos em expansão, como o recente caso da Braskem. A Braskem tornou-se a maior produtora de polímeros do país, com um extenso portfolio de produtos e seu caso aponta uma saída para a competitividade das empresas nessa indústria, em plena era da globalização.

No que tange à inovação tecnológica nessa indústria, Hemais et al ${ }^{[4]}$ relatam que os investimentos em P\&D feitos pelas empresas brasileiras da área, na década de 90 , não alcançaram os níveis atingidos na década anterior. A inibição dos investimentos em atividades de $\mathrm{P} \& \mathrm{D}$ em países como o Brasil, em que há fortes oscilações no cenário econômico, poderia ser explicado pelos riscos inerentes às atividades tecnológicas inovativas, especialmente em um período de forte transição, aliados à ciclicidade observada nos processo de expansão do setor de polímeros. 
Apesar de todas essas mudanças ocorridas na indústria na última década, "em termos de capacitação e competências das empresas brasileiras, é de se esperar que se mantenha a tendência de capacitação de operação das plantas e de adaptação da tecnologia adquirida por contratos de licenciamento...ao invés da ênfase em pesquisa fundamental associada ao desenvolvimento de novos produtos, como tem sido observado para as empresas líderes mundiais" $"[5]$.

No presente, essa indústria produz anualmente em torno de 4 milhões de toneladas de resina e é responsável pelo abastecimento total do mercado brasileiro de commodities poliméricas. Suas vendas correspondem a cerca de $1,5 \%$ do PIB do país. Considerando-se a cadeia petroquímica como um todo, englobando produtores de insumos, de polímeros e os transformadores, isto é, primeira, segunda e terceira gerações da cadeia, pode-se dizer que ela emprega cerca de 200 mil pessoas. Essa cadeia é formada por cerca de 6 mil empresas, que variam de grande porte (produtoras de insumos e de polímeros) a empresas de médio, pequeno e micro porte (transformadores de polímeros) $)^{[6-8]}$.

Hoje a indústria pode ser classificada como um grande produtor de polímeros do tipo commodity que representam, em geral, tecnologias sedimentadas, disponíveis de diversas fontes, que têm seus ciclos completamente dominados e em fase de maturação. A indústria se caracteriza, também, por controle completo de seu processo produtivo, tendo algumas empresas desenvolvido grades específicos, a partir de desenvolvimentos endóginos, e feito o desgargalamentos da produção.

Também são fabricados no Brasil alguns polímeros do tipo quasi-commodity, como PET, poliuretano, policarbonato e poliamidas, por exemplo. Quanto a esses dois últimos, as unidades existentes apresentam escala de produção bem abaixo de similares internacionais, o que pode ser considerado um dado negativo quando se pensa em termos de competição global. Porém, essas plantas são as únicas existentes na América do Sul, o que lhes dá uma certa vantagem diferencial, uma vez que são fornecedores tradicionais, com reputação firmada entre os consumidores. ABS, uma típica resina quasicommodity, até há pouco tempo, era fabricada pela Nitriflex em uma unidade localizada no Polo de Camaçari. Essa unidade, entretanto, foi vendida a Bayer que, após algumas tentativas de reativar a produção, acabou desistindo, fechou a planta e passou a importar a resina da Alemanha. Atualmente, a empresa mantém na planta de Camaçari uma base de beneficiamento e tingimento de ABS importado ${ }^{[9]}$.

Por outro lado, polímeros do tipo especialidade, ou de alto desempenho, são disponíveis no país através de importação de grandes produtores internacionais, uma vez que não há produção nacional de tais materiais, que representam o estado da arte em termos de conteúdo tecnológico e que tem grande valor agregado. $\mathrm{O}$ fato das quantidades demandadas pelo país serem pequenas pode justificar a falta de fabricação local, uma vez que isto incidiria em grandes investimentos e escala de produção mínima, muito maior do que as necessidades de consumo do país. O que existe no Brasil na área é a atividade de tolling ou prestação de serviço de tingimento e/ou aditivação desses polímeros. Grandes produtores estrangeiros, visando atender seus clientes mundiais com fábricas no Brasil, e sem querer investir em plantas industriais próprias, que, provavelmente, seriam anti-econômicas, mantêm no país essas atividades de prestação de serviço, a partir de polímeros importados ${ }^{[9]}$.

A esse respeito, merece destaque a indústria automobilística que, fabricando no Brasil "carros mundiais", necessitam padronizar sua produção e exigem de seus fornecedores tradicionais os mesmos materiais utilizados nas fábricas localizadas em seus países de origem. O caso da GE, por exemplo, ilustra bem a situação, uma vez que a unidade da empresa, localizada em Campinas, é uma das maiores fornecedoras de polímeros de alto desempenho para as montadoras instaladas no país.

\section{A indústria automobilística e os polímeros}

Os plásticos têm demonstrado um alto índice de confiabilidade e muitas vantagens sobre os materiais tradicionais que vieram a substituir, tais como o aço, o alumínio e o vidro, por exemplo. Além de permitir maior flexibilidade de projeto e economia na produção, sua baixa densidade é essencial para a redução do consumo de combustíveis, uma vez que a substituição de materiais diversos por cerca de 100 quilos de plástico, em um carro pesando 1 tonelada, trará uma economia de combustível de 7,5\%. Aproximadamente, para 100 quilos de peças plásticas utilizadas em um veículo, 200 a 300 quilos de outros materiais deixam de ser consumidos, o que se reflete em seu peso final. Assim, um automóvel, com uma vida útil de 150 mil quilômetros, poderá economizar 750 litros de combustível devido a utilização dos plásticos ${ }^{[10]}$.

Dados norte-americanos informam que, como são produzidos naquele país 15 milhões de carros/ano, quasi 20 milhões de litros de gasolina são economizados e 4,7 milhões de toneladas de dióxido de carbono deixam de entrar na atmosfera devido ao uso de peças plásticas ${ }^{[11]}$.

No que se refere especificamente a ítens de segurança, os polímeros possibilitam a fabricação de pára-choques com propriedades de absorção de impacto, air-bags, proteções contra impacto lateral (que não lascam ou fraturam) e cintos de segurança, diminuindo de forma marcante os casos fatais em acidentes.

A Tabela 1 apresenta uma relação das principais vantagens e desvantagens identificadas no que se refere ao uso do plástico como parte integrante do automóvel. Observa-se que a relação proposta não esgota o assunto, que é muito mais amplo e complexo.

De uma forma geral, pode-se depreender que a principal vantagem advinda do uso de plásticos se refere à economia, tanto de combustível quanto de investimentos em produção. Por outro lado, existe a possibilidade de sofisticação do design, o uso de formas e soluções menos tradicionais e o aumento de segurança.

Quanto às desvantagens apontadas, elas se referem a itens que são comuns a maioria dos materiais plásticos. Entretanto, de acordo 
Tabela 1.Vantagens e desvantagens do uso de plásticos nos automóveis, em substituição a outros materiais

\begin{tabular}{l|l}
\hline \multicolumn{1}{c}{ Vantagens } & \multicolumn{1}{c}{ Desvantagens } \\
\hline redução de peso & $\begin{array}{l}\text { deterioração por ação } \\
\text { térmica e ambiental } \\
\text { inflamabilidade } \\
\text { redução da emissão de } \mathrm{CO}_{2} \\
\text { redução de custos }\end{array}$ \\
$\begin{array}{l}\text { redução do tempo de produção } \\
\text { menores investimento ao impacto } \\
\text { manufatura }\end{array}$ & $\begin{array}{l}\text { deformação permanente elevada } \\
\text { dificuldade de adesão } \\
\text { de película de tinta } \\
\text { aumento da resistência à } \\
\text { corrosão } \\
\text { possibilidade de designs mais } \\
\text { modernos } \\
\text { formatidade de manchas } \\
\text { permanentes } \\
\text { excelente processabilidade } \\
\text { veículos mais silenciosos } \\
\text { melhor uso de espaço } \\
\text { aumento de segurança }\end{array}$ \\
\hline
\end{tabular}

com a especificação necessária do material a ser utilizado, pode existir um tipo de polímero especialmente produzido para atender às exigências de uso, superando uma desvantagem encon- trada em um plástico comum. Por exemplo, a mistura de poli(óxido de metileno) e poliamida, disponível no mercado sob o nome de Noryl (marca registrada da GE), é um material com características especiais para receber pintura, além de ter excelente resistência ao impacto e altíssima estabilidade dimensional. Ainda, o poli(sulfeto de fenileno) é um material com alta resistência à chama, o que o torna ideal para aplicações que exijam esse tipo de propriedade.

Foram produzidos no mundo, em 2000, cerca de 59 milhões de veículos ${ }^{[12]}$. No Brasil, a produção em 2000 foi de 1,7 milhão de veículos e o faturamento dessa indústria, no valor de US\$20 milhões, representou $10,2 \%$ do PIB industrial brasileiro daquele ano, o que demonstra sua importância no cenário do país ${ }^{[13]}$.

Com base nesses números, partindo-se do princípio que um automóvel médio pesa em torno de 1 tonelada, e que cada veículo usa cerca de 100 quilos de plástico, isto é, aproximadamente $10 \%$ de seu peso, pode-se estimar que em 2000 a indústria automobilística mundial consumiu em torno de 6 milhões de toneladas de plástico. No Brasil, esse cálculo leva a um montante em torno de 170 mil toneladas de plástico.

A Tabela 2, elaborada a partir da contribuição de diversos autores $^{[11,14-17]}$, apresenta os principais polímeros utilizados na indústria automobilística, as propriedades que os fazem ser especiais para a finalidade, as peças produzidas, bem como seus fornecedores no Brasil.

Tabela 2. Principais polímeros utilizados na indústria automobilística

\begin{tabular}{|c|c|c|}
\hline Polímeros & Propriedades & Peças produzidas \\
\hline $\begin{array}{l}\text { Polietileno de } \\
\text { alta densidade } \\
\text { (HDPE) } \\
\text { (Fabricante no } \\
\text { Brasil: } \\
\text { Braskem; } \\
\text { Ipiranga; } \\
\text { Politeno; } \\
\text { Solvay) }\end{array}$ & $\begin{array}{l}\text { Resistência a calor } \\
\text { Resistência a solventes } \\
\text { Baixa permeabilidade } \\
\text { Boa processabilidade } \\
\text { Baixo custo }\end{array}$ & $\begin{array}{l}\text { Bombona de reserva; Caixa do triângulo de emergência; Proteção anti } \\
\text { cascalho; Reservatório de água do pára-brisa; Sistema de distribuição de } \\
\text { combustível; Tanque de combustível; }\end{array}$ \\
\hline $\begin{array}{l}\text { Polipropileno } \\
\text { (PP) e suas } \\
\text { composições } \\
\text { (Fabricante no } \\
\text { Brasil: } \\
\text { Borealis/ } \\
\text { Braskem; } \\
\text { Branco/Dow; } \\
\text { Braskem; } \\
\text { Ipiranga; } \\
\text { Polibrasil) }\end{array}$ & $\begin{array}{l}\text { Alta resistência química e a solventes } \\
\text { Boa estabilidade dimensional } \\
\text { Flexibilidade } \\
\text { Durabilidade } \\
\text { Baixos custos } \\
\text { Excelente balanço impacto/rigidez } \\
\text { Boa resistência às intempéries } \\
\text { Boa resistência a riscos }\end{array}$ & $\begin{array}{l}\text { Bandeja traseira (sobre o porta-malas); Caixa da bateria; Caixa de calefação; } \\
\text { Caixa de ferramentas; Caixa de primeiros socorros; Caixa do cinto de } \\
\text { segurança; Caixa do retrovisor interno; Caixa elétrica central; Calotas; } \\
\text { Carpetes; Cobertura da bateria (proteção da parte superior, prevenção contra } \\
\text { curto-circuito); Cobertura do volante; Cobertura dos amortecedores; } \\
\text { Conduto de aspiração de ar; Condutos de ar; Condutos de ar; Conjunto de } \\
\text { regulagem dos bancos; Console; Corpo do filtro de ar; Depósito de } \\
\text { expansão da água de refrigeração do motor; Depósito do fluido de freio; } \\
\text { Empunhadura do freio de mão; Estribo de acesso das portas; Frisos laterais; } \\
\text { Grades de circulação de ar; Inserto (alma) do encosto de cabeça; Inserto } \\
\text { (alma) do quebra-sol; Inserto do descansa braço; Painéis das portas; Painel } \\
\text { de instrumentos; Pára-choques; Porta-cassetes; Porta-luvas; Proteção da } \\
\text { borda dos pára-lamas; Proteção da correia dentada; Proteção do ventilador } \\
\text { do radiador; Revestimento da coluna de direção; Revestimento das colunas; } \\
\text { Revestimento do marco da porta; Revestimento do porta-malas; } \\
\text { Revestimento do teto (interno); Revestimento dos bancos; Revestimento } \\
\text { interior dos pára-lamas; Revestimento interior traseiro; Revestimento lateral } \\
\text { do teto (interno); Spoiler traseiro (porta-malas); Spoiler traseiro (teto); } \\
\text { Tampas da bateria; Ventilador }\end{array}$ \\
\hline
\end{tabular}




\begin{tabular}{ll}
\hline $\begin{array}{l}\text { Poli(óxido de } \\
\text { metileno) }\end{array}$ & Excelente estabilidade dimensional; \\
(POM) & Baixa absorção de água \\
e seus & Resistência à fricção \\
copolímeros & Alta resistência à fadiga
\end{tabular}

(Não fabricado no Brasil)
Movimentação dos vidros das portas; Manivela de movimentação dos vidros das portas; Guia dos vidros das portas; Engrenagens do motoredutor do sistema de movimentação dos vidros das portas; Limpadores de pára-brisa; Engrenagens do motoredutor do sistema de acionamento do limpador; Cintos de segurança;

Ancoragem do cinto de segurança na coluna do veículo; Dispositivo de retração; Espelhos retrovisores; Coxim e elementos deslizantes; Carcaça e engrenagens do motoredutor do sistema de movimentação do espelho; Suporte do espelho retrovisor; Fechaduras; Carcaça do mecanismo de fechamento; Corpo de fechamento da tampa do porta malas; Engrenagens do sistema de fechamento centralizado; Circuito de combustível; Bóia do carburador; Carcaça do filtro de combustível; Componentes da bomba de combustível; Gargalo de alimentação do combustível; Tampa do gargalo de alimentação de combustível; Válvula anti-retorno de combustível

\section{Exterior}

Alavanca da abertura das portas; Grampos para instalação dos frisos laterais; Guias de movimentação do teto solar; Parte dos pára-choques

\section{Interior}

Alavanca de rebatimento do encosto dos bancos dianteiros (veículos de 2 portas); Alavanca de abertura da tampa do porta malas; Alavancas de comando dos limpadores de pára-brisa e das setas; Guia de deslocamento dos bancos; Manivela de regulagem de posição do encosto dos bancos; Suporte do quebra-sol

Suporte do encosto de cabeça; Tampa dos alto-falantes; Sistemas de frenagem, transmissão, amortecimento e direção; Elemento de regulagem dos faróis; Elementos deslizantes da coluna de direção; Engrenagens do sistema de embreagem; Suporte da alavanca das marchas; Terminais do chicote de cabos; Válvula do servofreio; Sistema de calefação; Alavancas de regulagem; Engrenagens dos comandos do sistema de calefação

\section{Outros}

Manivela de movimentação do teto solar; Partes do macaco para elevação do veículo; Pistão do sistema de transmissão hidráulica; Rotor da bomba d'água; Terminal do cabo de embreagem

\section{Polímeros \\ fluorados \\ Politetrafluo- \\ roetileno \\ (PTFE) e suas \\ composições \\ (Fabricante no \\ Brasil: \\ Du Pont (*)}

Alta resistência térmica

Resistência a óleo

Resistência a agentes químicos
Bomba de combustível elétrica; Elemento deslizante do amortecedor; Elemento deslizante do freio; Guia do pistão do amortecedor; Indicador de desgaste de freio
Poli(teleftalato de butileno) (PBT) Poli(teleftalato de butileno) de alto impacto (PBT-HI)

(Fabricante no Brasil: $G E(*)$ Rhodia)
Boa resistência mecânica Boa resistência térmica Boa estabilidade dimensional Baixa absorção de água Isolamento elétrico
Ancoragem dos retrovisores laterais; Caixa de conectores do sistema elétrico; Calota; Carcaça da bomba do circuito de água para o pára-brisa; Carcaça do motoredutor do sistema de movimentação dos vidros; Carcaça do motoredutor dos limpadores de pára-brisa; Carcaça do sistema de ignição (distribuidor); Carcaça dos faróis; Cinzeiros; Comando do sistema de movimentação dos vidros; Conectores; Elementos de regulagem dos faróis; Estojo de fusível; Grades; Palhetas dos limpadores de pára-brisa; Pára-lama; Pistão do servofreio; Porta-escovas de motores elétricos; Relés; Suporte do regulador dos 
Polímeros de

líquido-

cristalinos

(LCP)

(Não Fabricado no Brasil)

Poli(sulfeto de fenileno) (PPS)

(Não Fabricado no Brasil)
Resistência ao calor

Auto-retardante de chama

Baixa absorção de água

Alta resistência mecânica

Excelente resistência química

Fácil processabilidade retrovisores laterais; Tampa do air-bag

Conectores; Porta-escovas de motores elétricos; Suporte da bobina

\section{Elevada rigidez}

Excelentes propriedades mecânicas

Transparência a micro-ondar

Excelentes propriedades elétricas

Fácil processabilidade

Auto-retardamento de chama
Carcaça dos faróis; Paletas da bomba de vácuo; Suporte da bobina; Suporte do porta-escovas do motor de refrigeração; Válvulas do filtro de ar

\begin{tabular}{|c|c|c|}
\hline $\begin{array}{l}\text { Policarbonato } \\
\text { (PC) } \\
\text { (Fabricante no } \\
\text { Brasil: GE }\left(^{*}\right) e \\
\text { Policarbonato) }\end{array}$ & $\begin{array}{l}\text { Semelhança a vidro } \\
\text { Alta resistência ao impacto } \\
\text { Boa estabilidade dimensional } \\
\text { Boas propriedades elétricas } \\
\text { Boa resistência às intempéries } \\
\text { Resistência à chama } \\
\text { Capacidade de refletir a luz } \\
\text { Estabilidade a radiações de ultravioleta }\end{array}$ & Faróis; Lanternas; Painel de instrumento \\
\hline $\begin{array}{l}\text { Poliuretano } \\
\text { (PU) } \\
\text { (Fabricante no } \\
\text { Brasil: Basf, } \\
\text { Bayer, Resana) }\end{array}$ & $\begin{array}{l}\text { Excepcional resistência a abrasão } \\
\text { Absorvedor de energia } \\
\text { Isolamento acústico } \\
\text { Fácil processabilidade }\end{array}$ & $\begin{array}{l}\text { Pára-choque; Estofo dos bancos; Coxins; Tapes Suporte do motor; } \\
\text { Enchimento do pára-choque; }\end{array}$ \\
\hline $\begin{array}{l}\text { Poliamida (PA) } \\
\text { (Fabricante no } \\
\text { Brasil: } \\
\text { Mazzaferro, } \\
\text { Rhodia) }\end{array}$ & $\begin{array}{l}\text { Boa processabilidade } \\
\text { Resistência à tensão } \\
\text { Resistência a alta temperatura } \\
\text { Excelente estabilidade dimensional }\end{array}$ & $\begin{array}{l}\text { Dutos de captação de ar; Engrenagens; Conectores de sistema de injeção; } \\
\text { Sistema de freio de estacionamento; Escaninho do airbag }\end{array}$ \\
\hline
\end{tabular}

Poli(metacrilato Semelhança ao vidro

de metila) Boa resistência química

(Fabricante no Transparência
(PMMA) Alta resistência às intempéries

Brasil:

Metacryl)
Copoli(estirenobutadienoacrilonitrila) (ABS) Brasil: $G E$ (*), Bayer)

Copoli(estirenoacrilonitrila) (SAN)

(Fabricante no Brasil: Bayer) vinila) (PVC)

(Fabricante no Alta resistência à chama Semelhança a couro Flexibilidade de processamento Alta resistência química Ótima processabilidade Resistência ao impacto

Resistência à intempéries Ótima processabilidade Resistência ao impacto
(Fabricante no

Poli(cloreto de

Fibras ótica; Lanternas; Protetos de chuca nas janelas

Resistência à corrosão Resistência a baixas temperaturas Grande estabilidade dimensional Grades de ventilação

Grades; Calotas; Painel de instrumentos; Carcaça de lanterna Resistência a baixas temperaturas

Brasil: Braskem, Solvay)
Filtros de ar e de óleo; Revestimento de bancos; Painéis e interiores; Revestimento de fios e cabos elétricos 


$\begin{array}{lll}\begin{array}{l}\text { Poli(óxido de } \\ \text { metileno)/ }\end{array} & \begin{array}{l}\text { Boa resistência a impacto } \\ \text { Alta resistência a solventes }\end{array} & \text { Pára-lama } \\ \text { poliamida } & \text { Boa resistência a alta temperatura } & \\ \text { (Noryl GTX) } & \text { Baixa absorção de umidade } & \\ (\text { Fabricante no } & \text { Fácil colagem e pintura } & \text { Ótima processabilidade } \\ \text { Brasil: } G E(*)) & \text { Excepcional brilho }\end{array}$

\begin{tabular}{lll}
\hline $\begin{array}{l}\text { Poli(tereftalato } \\
\text { de butileno)/ }\end{array}$ & Excelente resistência mecânica & \\
Policarbonato & Alta resistência às intempéries & Painel de instrumento \\
(Xenoy) & Resistência a altas temperaturas & Pára-choque lateral externo \\
& Retenção de cor & Ponteira de pára-choque \\
(Fabricante no & Resistência a ultravioleta & Spoilers \\
Brasil: $G E(*))$ &
\end{tabular}

Poli(tereftalato Alta resistência mecânica de etileno) Alta resistência térmica

(PET) Alta resistência química

(Fabricante no $\quad \begin{aligned} & \text { Transparência } \\ & \text { Alta impermeabilidade }\end{aligned}$

$\begin{array}{ll}\text { Brasil: } & \text { Fácil processabilidade }\end{array}$

Nordeste,

Rhodia)

(*) Fornecedores dos polímeros e composições, a partir de matéria-prima importada

Pode-se verificar, de imediato, conforme observado anteriormente, que só os polímeros tipo commodity e quasicommodity são fabricados no país. Por outro lado, verifica-se que nenhuma resina do tipo especialidade é fabricada no país, sendo todo o abastecimento feito por importação. Entretanto, existe uma tendência no Brasil, de substituir as peças fabricadas com polímeros de alto desempenho por similares feitos com composições de polipropileno, mais baratas, o que fez com que as vendas desse polímero expandissem, em 2001, em torno de $4 \%$, em relação a $2000^{[9]}$.

Nesse segmento, aparece com destaque a GE como a principal fornecedora de produtos de alto desempenho, especialmente destinados à indústria automobilística.

\section{Automóveis, polímeros e inovação tecnológica}

Em nível internacional, o relacionamento entre as indústrias de polímeros e de veículos tem sido intenso e bastante profícuo. Conforme observado anteriormente, a presença de peças plásticas nos automóveis foi fundamental para se conseguir melhores padrões de segurança, economia de combustível e flexibilidade de manufatura.

Ao longo dos anos, os consumidores se tornaram mais exigentes em relação aos produtos que adquirem. Eles querem carros que tenham alta performance, porém não consideram menos importantes ítens como confiabilidade, segurança, conforto, economia, estilo, preço competitivo e, cada vez mais, respeito ao meio ambiente. Somente os materiais plásticos podem responder aos desafios advindos dessas demandas conflitantes. Ainda, a crescente personalização que o consumidor espera dos veículos, fazendo com que aumentem os chamados produtos tailor-made, faz prever que a diversidade se tornará, em pouco tempo, a regra em vez de exceção - e somente a versatilidade e a flexibilidade dos plásticos permitirão que se fabriquem diferentes carros, baseados no mesmo chassis ${ }^{[10]}$.

Preve-se, portanto, que essas duas indústrias não deverão dissociar seus rumos por muitos e muitos anos de modo a, cada vez mais, cumprir o desafio de fabricar veículos seguros, econômicos e confortáveis, dentro de avançados padrões tecnológicos.

No que se refere ao Brasil, pode-se afirmar que a indústria automobilística foi uma das grandes catalisadoras da introdução de inovações tecnológicas na indústria de polímeros. Isto se tornou mais real a partir da fabricação no país dos "carros mundiais", quando as subsidiárias nacionais das montadoras passaram a exigir produtos que tivessem os mesmos padrões aprovados pelas suas matrizes, em seus países de origem.

A indústria automobilística encontra no Brasil um grande fabricante de polímeros para usos gerais e para alguns usos especiais e que está preparado, por esforço próprio, para atender, através de fornecimento tailor-made, às crescentes exigências das montadoras. Essa autonomia tecnológica também faz com que o país seja um importante fabricante de compostos poliméricos, especialmente desenvolvidos para suprir as necessidades dessas montadoras. Além disso, a indústria de polímeros no Brasil é, de longe, a mais importante da América do Sul, sendo, por isso, um destacado fornecedor para montadoras de automóveis em outros países latinos, especialmente a Argentina.

Entretanto, conforme já mencionado, peças plásticas, que demandem situações extremas de uso, são confeccionadas no país a partir de matéria-prima importada. Essas peças utilizam polímeros que representam o que existe de mais avançado tecnologicamente na área. Por um lado, sabe-se que as quantidades demandadas por esses materiais no país são pequenas, não justificando a produção dos mesmos em esca- 
las mínimas que seriam, na melhor das hipóteses, anti-econômicos. Por outro lado, existe todo um processo de nãoglobalização tecnológica na área de polímeros, centralizando em poucos fornecedores mundiais tecnologias o que representa o estado da arte no setor, conforme discutido por Hemais et al ${ }^{[4]}$. É de se esperar que haja grande dificuldade para que empresas nacionais consigam licenciar o que existe de mais atual em matéria de tecnologia em polímeros, caso desejem produzir no país esses materiais mais sofisticados.

A realidade nacional mostra a existência de empresas produtoras de polímeros excessivamente comprometidas com $\mathrm{P} \& \mathrm{D}$ de curto prazo, tentando adaptar seus produtos às condições do país e diferenciá-los para ganhar nichos de mercado, nos quais conseguem se fazer competitivas face às multinacionais de grande porte e nisso elas se destacam com grande sucesso. Essas empresas, contudo, negligenciam os desenvolvimentos de longo prazo, que trazem consigo um alto grau de incerteza e de imprevisibilidade, mas que poderiam garantir altos ganhos (tanto financeiro, quanto de competitividade) no futuro ${ }^{[18]}$.

\section{Conclusões}

Este trabalho apresentou um panorama do intenso relacionamento existente entre a indústria automobilística e a indústria de polímeros, em nível internacional, e como esse relacionamento ocorre no Brasil. As peças plásticas, cada vez mais, têm sua importância reconhecida como parte integrante dos automóveis, trazendo, acima de tudo, economia, segurança e flexibilidade para o produto final.

Para a indústria automobilística, o país se apresenta como um bem sucedido fornecedor de polímeros de usos gerais e de alguns polímeros de uso específico, incluindo compostos e misturas poliméricas. Entretanto, polímeros de alto desempenho, classificados como especialidades poliméricas, não são aqui produzidos.

Tendo como base o fornecimento à indústria automobilística, este trabalho pretendeu discutir a questão da criação endógena de tecnologia que represente o que existe de mais atual na área de polímeros, mostrando que isso, aparentemente, não é um ítem que merece a preocupação prioritária das empresas brasileiras do setor.

\section{Agradecimentos}

$\mathrm{O}$ autor agradece ao CNPq pelo suporte dado à presente pesquisa.

\section{Referência Bibliográfica}

1. APC (American Plastic Council) (1999) Plastic vehicles: making inroads in the automotive world, April 1999. Disponível em www.americanplasticscouncil.org.

2. Bomtempo, J. V. - Innovation et organisation: le cas de l'industrie des polymeres, Tese de Doutorado, L'École Nationale Superiére des Mines de Paris, Paris (1994).
3. Fialho, B. C.; Hasenclever, L. \& Hemais, C. A. - Innovation, competencies and technological change in the polymer industry, The Tenth International Conference on Management of Technology - IAMOT 2001, Lausanne, Switzerland, 174BCF (2001).

4. Hemais, C. A., Rosa, E. O. R. \& Barros, H. M. - "A nãoglobalização tecnológica da indústria brasileira de polímeros medida através de patentes", Revista de Administração Contemporânea, 3 (3): 157-177 (1999).

5. Fialho, B. C.; Hasenclever, L. \& Hemais, C. A. - Aspectos teóricos da mudança tecnológica: uma análise exploratória da área de polímeros, ALTEC (Asociación LatinoIberoamericana de Gestión Tecnológica) 99 - Resúmenes y ponencias, VIII Seminario Latino-Iberoamericano de Gestión Tecnológica, Valencia, España, p.275 (1999).

6. ABIPLAST (Associação Brasileira da Indústria de Plásticos) (2000) Perfil 2000: Indústria Brasileira de Transformação de Material Plástico. São Paulo.

7. ABIQUIM (Associação Brasileira da Indústria Química e Derivados ) (2001). Anuário da indústria química brasileira 2001. São Paulo.

8. Perrone, O.V. (2001) A importância econômica dos polos petroquímicos brasileiros, palestra proferida no IMA/ UFRJ, Rio de Janeiro, Novembro.

9. Plástico no Brasil (2002), Plásticos em Revista, 40, 470, abril.

10. APME (Association of Plastic Manufacturers in Europe) (1999) A material for choice for the automotive industry, Summer 1999. Disponível em www.apme.org.

11. ALC (Automotive Learning Center) (2002) Plastic applications in cars. Disponível em www.plastics-car.com.

12. EIU (Economist Inteligence Unit ) (2002) Production of all vehicles by region. Disponível em http:// askauto.com/statistic.htm.

13. ANFAVEA (Associação Nacional dos Fabricantes de Veículos Automotores) (2002) Anuário Estatístico da Indústria Automobilística Brasileira, São Paulo.

14. Rodrigues, R.A. (2002) Comunicação pessoal, DMK/ DMESP- Ipiranga Petroquímica, Triunfo, Rio Grande do Sul $(29 / 8 / 02)$.

15. Mano, E. B. (1991) Polímeros como materiais de engenharia, São Paulo: E. Blucher.

16. Mano, E.B. \& Mendes, L.C. (1999) Introdução a polímeros, $2^{\mathrm{a}}$ edição, São Paulo: E. Blucher.

17. GE Plastics - Helping customers gain competitive advantages. Disponível em www.geplastics.com (2002)

18. Hemais, C. A.; Barros, H. M. \& Rosa, E. O. R. - "The evolution of R\&D laboratories in the Brazilian polymer industry“, Latin American Business Review, no prelo (2003).

Recebido: $17 / 09 / 02$

Aprovado: 12/02/03 